\title{
Relative Stability of Silicon Self-Interstitial Defects
}

G. Subramanian, K.S. Jones, M.E. Law, M.J. Caturla, S. Theiss, T. Diaz de la Rubia

This article was submitted to

Materials Research Society, San Francisco, CA

April 24-28, 2000

\section{April 11, 2000}

U.S. Department of Energy

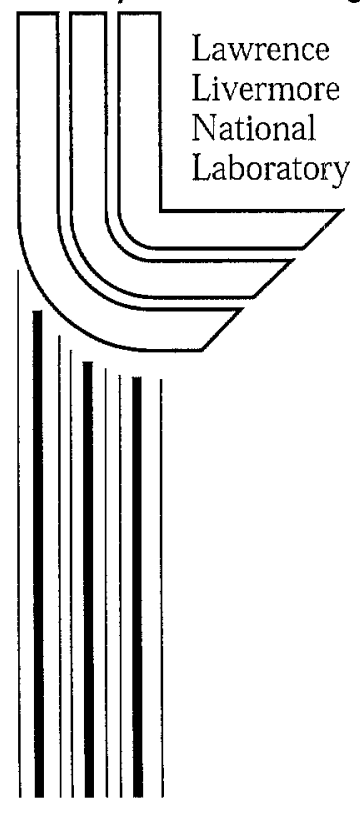




\section{DISCLAIMER}

This document was prepared as an account of work sponsored by an agency of the United States Government. Neither the United States Government nor the University of California nor any of their employees, makes any warranty, express or implied, or assumes any legal liability or responsibility for the accuracy, completeness, or usefulness of any information, apparatus, product, or process disclosed, or represents that its use would not infringe privately owned rights. Reference herein to any specific commercial product, process, or service by trade name, trademark, manufacturer, or otherwise, does not necessarily constitute or imply its endorsement, recommendation, or favoring by the United States Government or the University of California. The views and opinions of authors expressed herein do not necessarily state or reflect those of the United States Government or the University of California, and shall not be used for advertising or product endorsement purposes.

This is a preprint of a paper intended for publication in a journal or proceedings. Since changes may be made before publication, this preprint is made available with the understanding that it will not be cited or reproduced without the permission of the author.

This report has been reproduced directly from the best available copy.

Available electronically at http://www.doc.gov/bridge

Available for a processing fee to U.S. Department of Energy

And its contractors in paper from

U.S. Department of Energy

Office of Scientific and Technical Information

P.O. Box 62

Oak Ridge, TN 37831-0062

Telephone: (865) 576-8401

Facsimile: (865) 576-5728

E-mail: reports@adonis.osti.gov

Available for the sale to the public from

U.S. Department of Commerce

National Technical Information Service

5285 Port Royal Road

Springfield, VA 22161

Telephone: (800) 553-6847

Facsimile: (703) 605-6900

E-mail: orders@ntis.fedworld.gov

Online ordering: http://www.ntis.gov/ordering.htm

OR

Lawrence Livermore National Laboratory

Technical Information Department's Digital Library

http://www.llnl.gov/tid/Library.html 


\title{
Relative Stability of Silicon Self-Interstitial Defects
}

\author{
G.Subramanian*, K.S. Jones*, M.E.Law**, M.J.Caturla***, S.Theiss***, T.Diaz \\ de la Rubia*** \\ *Department of Materials Science \& Engineering, 525 Engineering Bldg. \\ **Department of Electrical and Computer Engineering, 525 Engineering Bldg. \\ SWAMP Center, University of Florida, P.O.Box 116400, Gainesville, FL 32611 \\ ***Lawrence Livermore National Laboratory, Livermore, CA 94550
}

\section{ABSTRACT}

\{311) defects and dislocation loops are formed after ion-implantation and annealing of a silicon wafer. Recent Transmission Electron Microscopy studies by $\mathrm{Li}$ and Jones have shown that sub-threshold dislocation loops nucleate from $\{311\}$ defects. In our study, the conjugate gradient method with the Stillinger Weber potential is used to relax different configurations such as $\{311\}$ defects with a maximum of five chains and perfect dislocation loops. From the formation energies thus obtained we find that there is an optimal width for each length of the $\{311\}$ defects. Moreover the relative stability of $\{311\} \mathrm{s}$ and loops is studied as a function of defect size. We observe that at very small sizes the perfect loops are more stable than the $\{311\}$ s. This may provide an explanation for the experimental observation by Robertson et al that, in an annealing study of end of range damage of amorphized samples, $45 \%$ of the loops had nucleated in the first 10 minutes of anneal. We propose that homogeneous nucleation, as against unfaulting of the $\{311\} \mathrm{s}$, could be the source of these loops.

\section{INTRODUCTION}

Shallow junctions, produced by ion-implantation, are a necessity if microelectronic devices of smaller dimensions are to be realized. It is well known that $\{311\}$ defects and dislocation loops are formed upon annealing subsequent to ion-implantation. It is also known that $\{311\}$ defects, as a source of interstitials, contribute significantly to the phenomenon of transient enhanced diffusion (TED) of dopants such as boron in ion implanted silicon during post-implant annealing [1]. Transient enhanced diffusion has a deleterious effect on the formation of shallow junctions The formation and evolution of these $\{311\}$ defects is of great interest to researchers. On the other hand, the source of dislocation loops has been a subject of conjecture for a number of years. It has been observed by transmission electron microscopy (TEM) that concomitant with the dissolution of $\{311\}$ defects, some small loops grow in size [2]. Similar connection between the 
dissolution of $\{311\}$ defects and the growth of loops has been observed by other groups [3].

Recently, Li and Jones have shown through TEM studies that subthreshold dislocation loops nucleate from $\{311\}$ defects by unfaulting of the latter [4]. Robertson et al have reported that in the case of end-of-range damage of ion implanted silicon $45 \%$ of the dislocation loops were formed in the first 10 minutes of anneal [5]. In this work, we report, for the first time, through simulations, the stability of the $\{311\}$ defects depending on the length and width of the interstitial chains that constitute this defect. We also analyze, through simulations, the relative stability of the $\{311\}$ defects and perfect dislocation loops. The methodology of the simulations has been the conjugate gradient technique using the Stillinger -Weber (SW) [6] interatomic potential.

\section{COMPUTATIONAL DETAILS}

The Stillinger-Weber potential used in this work is the most widely used interatomic potential for silicon. In our simulations, we used a 27000 atom computational cell. This large cell size ensures that the lattice displacement field created by the relaxed extended defects is contained within the cell. For $\{311\}$ defects the interstitial configuration used here is similar to that used by Kim et al [7]. The interstitial chains constituting the $\{311\}$ defect are extended along the $<011>$ direction and they lie on the $\{311\}$ plane. Laterally, the interstitital chains are added along the $<233>$ direction. The adjacent interstitial chains are separated from each other by a distance of $\frac{a \sqrt{11}}{2 \sqrt{2}}$ where $a$ is the lattice parameter. This configuration is then relaxed using the conjugate gradient method with the $\mathrm{SW}$ interatomic potential. As a consequence of this relaxation we obtain the formation energy of the $\{311\}$ defects as a function of the number of interstitials in the defect. Calculations are done for different number of chains up to a configuration five chains wide. Similarly, the circular configuration of the perfect dislocation loop is created with Burgers vector $a / 2<110>$. Subsequently, the loop configuration is relaxed using the conjugate gradient method to yield formation energies for varying loop size.

\section{RESULTS AND DISCUSSION}

The total formation energies obtained using the conjugate gradient method are plotted in fig(1) as a function of number of interstitials. It is evident from this figure that as the defect size increases, the least energy configuration has progressively increasing widths. This trend is for the first four chains only. The 
five-chain wide defect has a higher formation energy compared to the four- chain wide defect for the defect sizes accessible from this simulation. A closer inspection of the data suggests that the five-chain defect will become more stable than the four-chain defect at a larger defect size.

Fig(2) shows the formation energy per interstitial of the $\{311\}$ defect as a

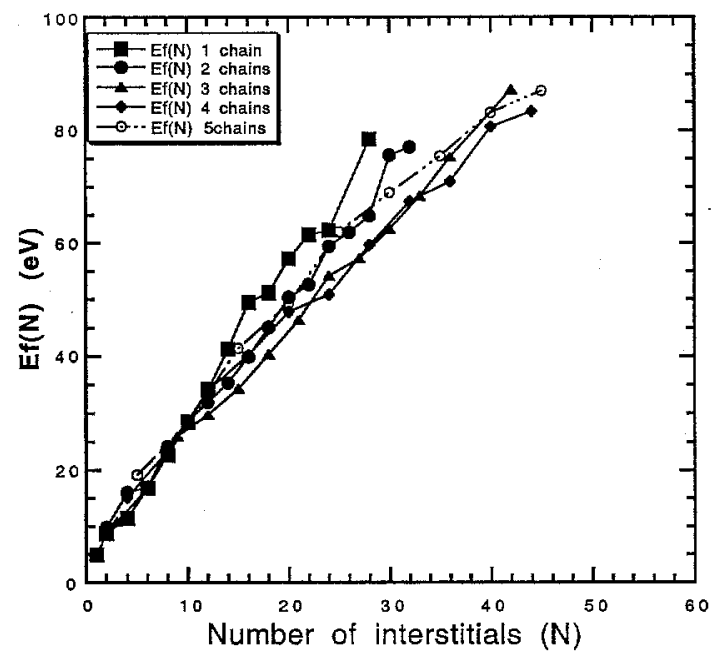

Fig 1: Formation energy versus defect size of $\{311\}$ defect for different number of chains

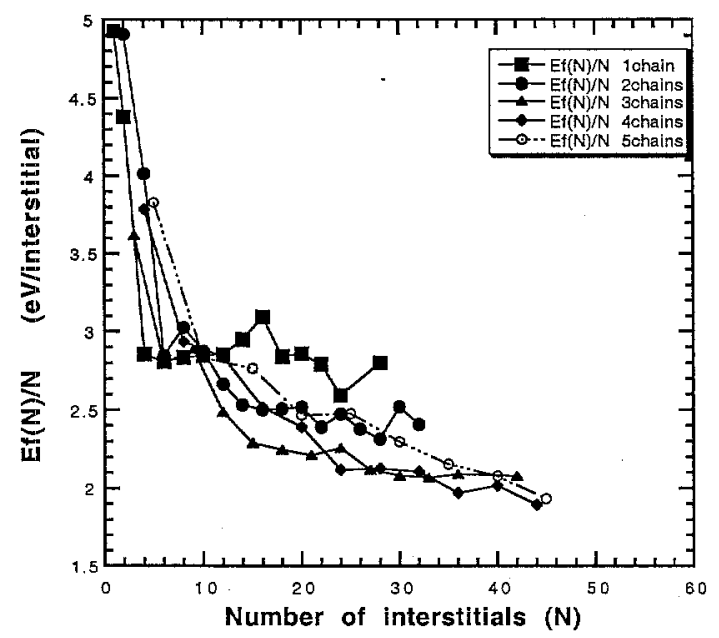

Fig 2: Formation energy per interstitial versus defect size of $\{311\}$ defect for different number of chains 
function of the defect size for different number of chains that constitute the defect. This figure demonstrates that the formation energy of the defect decreases as the defect size increases. Moreover, as in fig(1), the trend seems to be that the most stable defect width (number of chains) increases as the defect size increases. The formation energy per interstitial curves (fig(3)) for the perfect loop and $\{311\} \mathrm{s}$ show a decreasing energy trend with increasing defect size. Moreover, the formation energy per interstitial curve for the perfect loop follows closely the most stable $\{311\}$ energy curves for defect sizes greater than 20 interstitials. Fig(4) (after Robertson et al [5]) shows the percentage of loop nucleation as a function of anneal time. It is evident from this plot that $45 \%$ of loops were nucleated during the first $10 \mathrm{~min}$ of anneal. We propose that homogeneous nucleation as opposed to $\{311\}$ unfaulting may be the dominant mechanism of loop nucleation during this time interval. Unfaulting of the $\{311\}$ s occurs after a further anneal at $750^{\circ} \mathrm{C}$, thereby suggesting that there is an energy barrier for the unfaulting process.

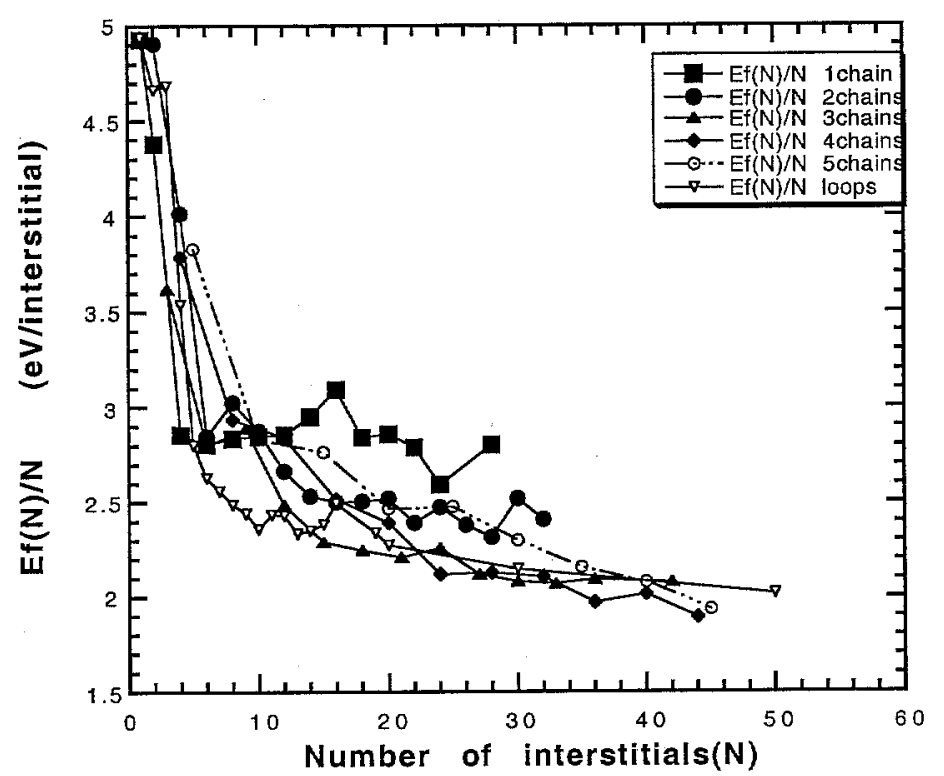

Fig.3: Formation energy per interstitial versus defect size for $\{311\}$ defect with different number of chains and for perfect dislocation loop 


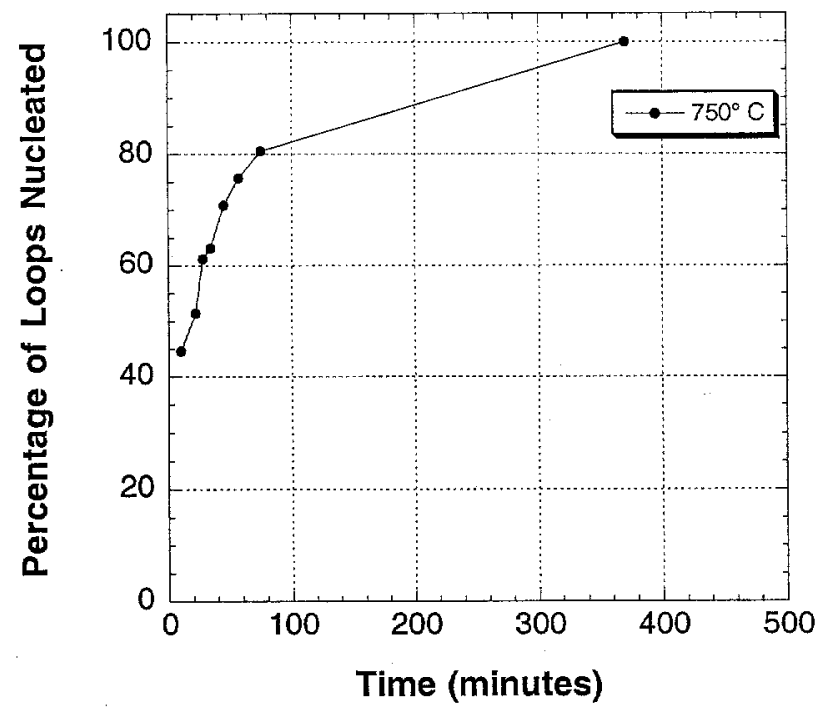

Fig.4: Percentage of dislocation loops formed as a function of annealing time. (After Robertson et al [5])

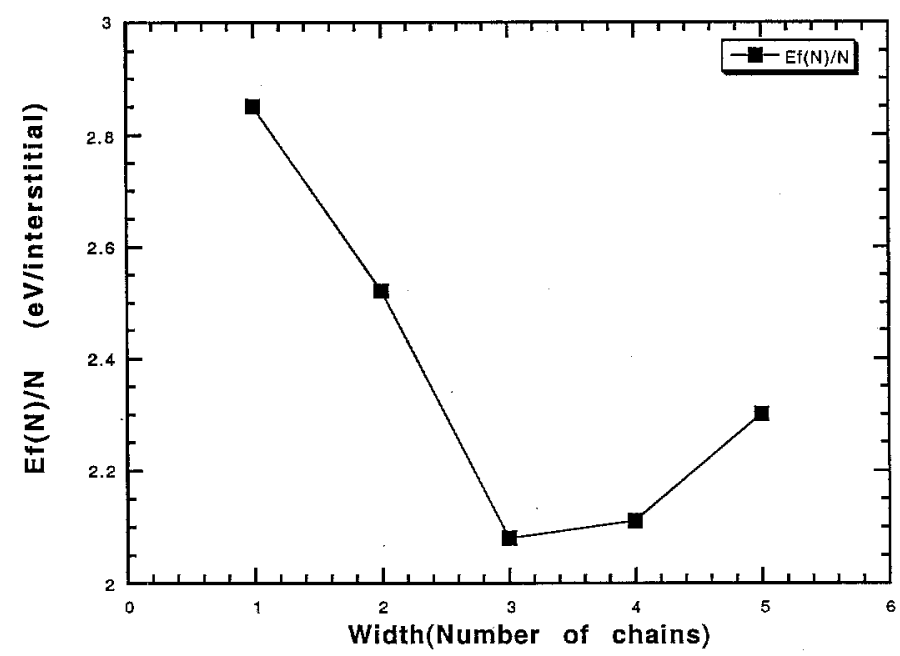

Fig.5: Formation energy per interstitial versus width (Number of chains) for $\{311\}$ defect size $N=30$ 
Fig. 5 depicts the formation energy per interstital as a function of width (number of chains) for a defect size of 30 interstitials. This helps in understanding the trend of energy values vs width size indicating the relative stability of $\{311\}$ defects for different number of chains.

\section{CONCLUSIONS}

We have done atomisitic simulations using the conjugate gradient method with the Stillinger-Weber potential to obtain the formation energy of $\{311\}$ defects for defect widths up to 5 chains. We observe that the most stable $\{311\}$ defect has progressively increasing width with increasing defect sizefor the defect sizes studied. We have also computed the formation energy of perfect dislocation loops for increasing number of interstitials in the defect. It is observed that the formation energy curve of the loops is aligned with the formation energy curve of the most stable $\{311\}$ defect for defect sizes greater than 20 interstitials. We conclude that nucleation of loops, during the initial 10 minutes of anneal at $750^{\circ} \mathrm{C}$ may be due to homogeneous nucleation and that subsequently, there is a energy barrier for unfaulting of the $\{311\}$ s to form loops. This unfaulting occurs during further anneals at $750^{\circ} \mathrm{C}$.

This work is performed under the auspices of U.S. Department of Energy by University of California Lawrence Livermore National Laboratory under contract No. W-7405-Eng-48.

\section{REFERENCES}

1. D. J. Eaglesham, P. A. Stolk, H.J. Gossman and J. M. Poate, Appl. Phys. Lett. 65, 2305 (1994).

2. W. K. Wu and J. Washburn, J.Appl.Phys.48, 3744 (1977).

3. T. Y.Tan, Phil. Mag., 44, 101 (1981).

4. Jinghong Li and Kevin S. Jones, Appl. Phys. Lett. 73 (25), 3748 (1998)

5. L. S. Robertson, K.S.Jones, L.M.Rubin and J.Jackson, J.Appl.Phys. 87(6), 2910 (2000).

6. Frank H. Stillinger and Thomas A. Weber, Phys. Rev. B, 31, 5262 (1985).

7. Jeongnim Kim, John W. Wilkins, Furrukh S. Khan, Andrew Canning, Phys. Rev. B, 55 (24), 16186 (1997). 